\title{
Home-Based Activity Program for Older People With Depressive Symptoms: DeLLITE-A Randomized Controlled Trial
}

\author{
Ngaire Kerse, $P b D, M B C b B$ \\ Karen J. Hayman, RN, MSc \\ Simon A. Moyes, MSc \\ Katby Peri, RN, MSHc \\ Elizabeth Robinson, MSc \\ Anthony Dowell, MD \\ Gregory S. Kolt, $\mathrm{PbD}$ \\ C. Raina Elley, PbD, MBCbB \\ Simon Hatcher, MD \\ Liz Kiata, MA \\ Janine Wiles, $P b D$ \\ Sally Keeling, $\mathrm{PbD}$ \\ Jobn Parsons, PT, MHSc \\ Bruce Arroll, $\mathrm{PbD}, \mathrm{MBCbB}$
}

\begin{abstract}
PURPOSE We wanted to assess the effectiveness of a home-based physical activity program, the Depression in Late Life Intervention Trial of Exercise (DeLLITE), in improving function, quality of life, and mood in older people with depressive symptoms.
\end{abstract}

METHODS We undertook a randomized controlled trial involving 193 people aged 75 years and older with depressive symptoms at enrollment who were recruited from primary health care practices in Auckland, New Zealand. Participants received either an individualized physical activity program or social visits to control for the contact time of the activity intervention delivered over 6 months. Primary outcome measures were function, a short physical performance battery comprising balance and mobility, and the Nottingham Extended Activities of Daily Living scale. Secondary outcome measures were quality of life, the Medical Outcomes Study 36-item short form, mood, Geriatric Depression Scale (GDS-15), physical activity, Auckland Heart Study Physical Activity Questionnaire, and self-report of falls. Repeated measures analyses tested the differential impact on outcomes over 12 months' follow-up.

RESULTS The mean age of the participants was 81 years, and 59\% were women. All participants scored in the at-risk category on the depression screen, 53\% had a Diagnostic and Statistical Manual of Mental Disorders or International Classification of Diseases, Tenth Revision diagnosis of major depression or scored more than 4 on the GDS-15 at baseline, indicating moderate or severe depression. Almost all participants, 187 (97\%), completed the trial. Overall there were no differences in the impact of the 2 interventions on outcomes. Mood and mental health related quality of life improved for both groups.

CONCLUSION The DeLLITE activity program improved mood and quality of life for older people with depressive symptoms as much as the effect of social visits. Future social and activity interventions should be tested against a true usual care control.

Ann Fam Med 2010;8:214-223. doi:10.1370/afm.1093.

\section{INTRODUCTION}

L ow mood in community-dwelling older people is common and is associated with poor physical function. ${ }^{1}$ Poor physical function predicts development of depression, ${ }^{2}$ disability, health service use, and institutionalization, ${ }^{3}$ and disability in turn predicts development of depression. ${ }^{2}$ Physical activity has the potential to interrupt the development of disability from both depression ${ }^{4}$ and poor physical function. ${ }^{5}$

Even small gains in physical performance and mood may result in significant benefits in functional status (ability to perform activities of daily living) and quality of life. ${ }^{6}$ Physical activity programs improve physical performance, ${ }^{7}$ and there are several established ways of promoting physical activity to older people, such as physician advice with community fol- 
low-up ${ }^{8}$ supervised group activity programs, and wider community level intervention. ${ }^{7,9}$ The most frail may require increased supervision with one-on-one personal trainer approaches. ${ }^{5}$ In considering older people with depressive symptoms, low mood is associated with poor participation in physical activity programs,${ }^{10}$ and so attention to choice and acceptability of activity is important to short-term and long-term sustainability for participants. Attention to the social context and promotion of moderately intense, rather than vigorously intense, activity promote participation. ${ }^{11}$ Older people are motivated by setting achievable goals. ${ }^{12}$

Success in improving function and reducing depressive symptoms with physical activity programs has been mixed, with an emphasis on gym-based training and supervised group sessions being more successful. High-quality trials are rare. ${ }^{13}$ Previous studies have been small, involved participants who were not recruited from primary care, or trials were not randomized, and rarely have they specifically enrolled older people.

For older people, low levels of social function are also integrally related to depression, ${ }^{14-16}$ and time spent in groups or activity programs can be an intervention in itself. Consequently, social contact matching the contact time involved in a physical activity program can be used to control for the social component of physical activity programs.

The DeLLITE trial developed a new activity program based on a proven home-based physical activity program ${ }^{17}$ enhanced with goal setting and social interaction. ${ }^{18}$ This trial assessed the effectiveness of this new physical activity program, controlling for social contact.

\section{METHODS}

\section{Trial Design}

DeLLITE, a randomized controlled trial lasting 12 months, tested the effect of a home-based physical activity program on physical function, quality of life, mood, and falls in an older community-dwelling population. The intervention group was compared with a group receiving social visits. The trial is reported according to the CONSORT statement ${ }^{19}$ and the quality of the trial met all criteria outlined for randomized controlled trials in the Users Guide to the Medical Literature $I I_{1}{ }^{20}$ except that double blinding was not possible. The Northern X Ethics Committee approved the study in $2004($ AKX/04/11/327).

\section{Participants and Recruitment}

Detailed recruitment procedures are reported elsewhere. ${ }^{18}$ Primary care practitioners in the central Auckland area were selected at random and invited to participate. Eligibility criteria of patients included that they were aged 75 years or older, were community dwelling, were able to communicate in English to complete assessments, and that they had no severe dementia or unstable medical conditions precluding participation in a physical activity program. A list of all registered patients in the age-group from participating practices was screened for eligibility by practice staff or the primary care practitioner, and all eligible patients were invited to participate by a letter from their primary care practitioner. The letter included the following validated 3 -question depression screen: (1) During the past month have you often been bothered by feeling down, depressed, or hopeless? (2) During the past month have you often been bothered by having little interest or pleasure in doing things? (3) Answer if you responded yes to 1 or 2: Is this something with which you would like help? ${ }^{21}$ Responses were returned to the research center. All patients not responding were telephoned and, where possible, the depression screen was administered over the telephone. Those who met inclusion criteria (answered yes to 2 of the 3 questions and passed a brief medical telephone screen or were medically cleared by their primary care practitioner) were invited to participate. Written, informed consent was obtained during a home visit from those who were eligible and interested. Participants were recruited from March 2006 to January 2007.

\section{Randomization and Blinding}

After recruitment and completion of baseline assessments, participants were randomized to a physical activity intervention or a social control group by a biostatistician not involved in recruitment using computergenerated random numbers. Couples were randomized to the same group to avoid intervention contamination The research nurses conducting follow-up assessments were blinded to the participants' group allocation. To maintain this blinding, immediately before the followup visits, participants were reminded by a telephone call from a researcher not to talk to the assessment nurses about the physical activity program or who had been visiting them.

\section{Intervention and Control Groups}

Physical Activity Intervention

Participants in the activity intervention group were given home-based individual instruction in a physical activity program by a trained nurse. The program was based on the Otago Exercise Program, which comprises moderate-intensity balance retraining, progressive resistance lower limb-strengthening exercises, and walking. ${ }^{17}$ Goal setting, social enrichment, and upper limb-strengthening exercises were added to the program, and the combined activity program was 
pilot tested during 2005. The participants identified a functional goal they wanted to achieve (eg, to be able to prune the roses or to walk around the house without using a walking stick), and they were encouraged to ask a social companion, family member, friend, or caregiver to help them exercise and meet the goal. The exercises and use of $1-, 2-$, or $3-\mathrm{kg}$ leg and arm weights were demonstrated and individually tailored to each participant's current level of ability. Participants were asked to do the exercises and to walk for at least 30 minutes 3 times a week where able. The intensity of the exercises was increased during the 6 -month intervention period to provide maximum functional benefit. Participants were visited 7 times during the first 3 months - at the initial assessment and again at week 1, $3,5,8,10$, and 12 - with a booster visit at 6 months to discuss any problems they were having with the exercises and to remind and remotivate them to complete the intervention program. Each visit was planned to last 1 hour; participants filled in calendars that they attached to the refrigerator to record their physical activity sessions, which they returned to the research center every month.

\section{Social Visits (Control Group)}

Participants in the control group received active social contact, but without physical activity, to control for the social contact received by the participants in the physical activity intervention group. Participants in the social control group were visited at the same intervals for an amount of time similar to that for the intervention participants. The social visitor used a conversational guide to standardize the topics to be discussed during the 8 visits. ${ }^{22}$ The guide suggested describing current social support patterns and the spatial and environmental patterns of these supports. It also ensured that no goal setting occurred, and no physical activity was facilitated during these visits. There was no psychotherapeutic component to the social visit discussions.

Participants in both groups were contacted by telephone during months 4 and 5, when there were no home visits.

\section{Uptake}

Adherence to the physical activity program was measured using the self-completed calendar recording the number of exercise episodes and walking frequency during the previous month. The calendar was either collected by the intervention nurse at a home visit or mailed back to the research center when there was no visit. Adherence was measured for 1 year. If the calendars were not received, participants were reminded by telephone until the 6-month follow-up period. There- after they were expected to continue to return them without reminders until a final reminder at 12 months.

\section{Outcomes and Follow-up}

All measures were ascertained using standardized procedures by an independent, trained research nurse during a home visit. Outcome measures, adverse events, and medication use were obtained at baseline, 6 months, and 12 months.

\section{Primary Outcome}

Physical function was ascertained by 2 measures. The first was a standardized set of direct observations, the Short Physical Performance Battery (SPPB), 3,23 including gait speed, muscle strength as measured by repeated standing from a chair, and a balance measurement. The second was the self-report Nottingham Extended Activities of Daily Living (NEADL) ${ }^{24}$ scale, a well-validated and frequently measure used to assess functional status and the ability to perform activities of daily living, such as mobility outside the home, meal preparation, shopping, and housekeeping.

\section{Secondary Outcomes}

Health-related quality of life was assessed with the SF-36, the Medical Outcomes Study short form health survey. ${ }^{25}$ Summary scores were calculated to provide the mental component summary score (MCS), and the physical component summary score (PCS). ${ }^{26}$ Mood was assessed with the Geriatric Depression Scale (GDS-15) a validated scale that accurately measures depressive symptomatology. ${ }^{27}$ Physical activity was assessed with the Auckland Heart Study Physical Activity Questionnaire, ${ }^{28}$ which elicits information about type, duration, and intensity of activities Adverse events, including falls, muscle pain, fatigue, and general aches and pains, were ascertained by self-report. Medications used were recorded by direct observation of the pill bottles.

Other measures gathered at baseline included demographic information, cognition assessed by the Abbreviated Mental Test Score, ${ }^{29}$ and history of and current diagnosis of depression assessed by the Composite International Diagnostic Interview (CIDI) $)^{30-32}$ depression module, which yields Diagnostic and Statistical Manual of Mental Disorders, Fourth Edition (DSM-IV ${ }^{33}$ ) and International Classification of Diseases, Tenth Edition (ICD-10 ${ }^{34}$ ) criteria for diagnosis of depression.

\section{Sample Size Calculation}

Sample size calculations used means, standard deviations, and estimated change in outcome. A sample size of 70 participants per group would have at least $90 \%$ power at the 0.05 level of significance to detect a true 
difference in the change of observed physical function (SPPB score) between the 2 groups. It would also have at least $90 \%$ power at the 0.05 level of significance to detect a clinically significant difference in the change in GDS-15 score of 1 point. ${ }^{35}$ This calculation assumes a standard deviation of the difference of 1.8 units based on information from the Visually Impaired Persons trial ${ }^{36}$ for the group who scored greater than 5 on the GDS-15, indicating significant depressive symptomatology. ${ }^{35}$ This sample size would also be adequate to show a clinically relevant change of 10 in the PCS of the SF-36 between groups $(\alpha=.05$; power of $80 \%$ ). Allowing for an attrition rate of $25 \%$ during the 12 months, 95 participants per group would be required. These participants were recruited over 10 months, at a rate of 24 per month, to allow for variation in mood and activity patterns over the seasons.

\section{Statistical Analysis}

Baseline characteristics were described for intervention and control groups. Repeated measures regression analyses were used to investigate whether there was a difference between intervention and control group change in outcomes over 12 months. Where there was no evidence of a differential change, the change over time in the combined groups is also reported. Where outcome measures were not normally distributed, these were logtransformed or converted to categorical variables for analysis using generalized linear mixed models (GLMM). The random effects in the models were to adjust for couples, as they had been randomly assigned the same treatment, and for primary care physician of origin as a potential cluster variable. Use of antidepressant medication was entered into the repeated measures analysis as a timedependent covariate when examining mood as an outcome.
All analyses used SAS version 9.1 (SAS Institute, Cary, North Carolina).

\section{RESULTS}

Of a total population of 2,276 potential participants invited from 42 primary care practices, 353 were eligible by depression screening criteria (Figure 1). Of these 353 eligible participants, 35 were not medically fit and 125 refused to participate (61\% response rate).

\section{Figure 1. Flow chart of participants through the DeLLITE trial.}

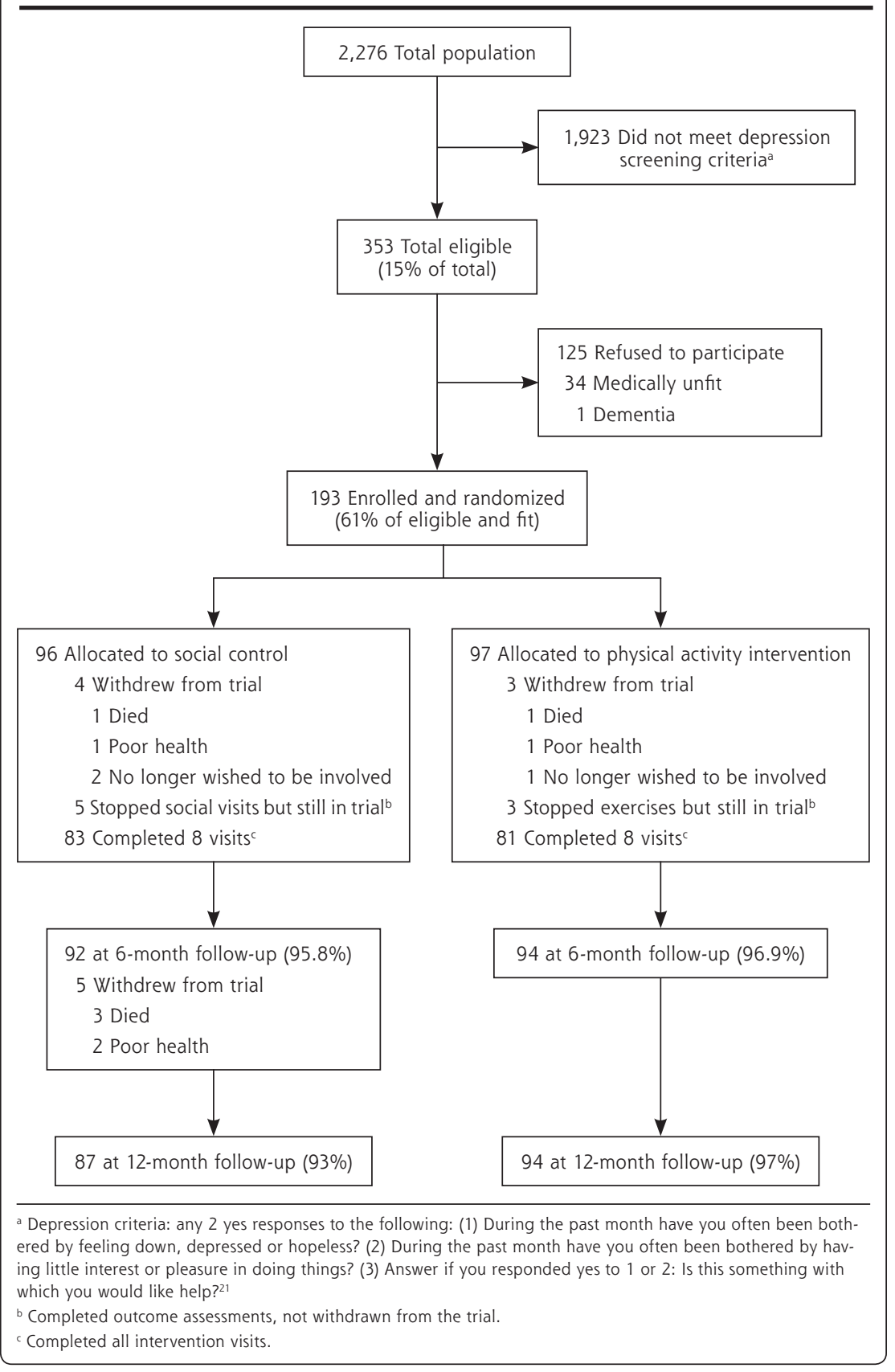


One hundred ninety-three participants were enrolled, and almost all (97\%) completed the trial. The group receiving social visits was similar to the activity intervention group on most baseline variables, although slightly more social group participants expressed

Table 1. Characteristics and Outcome Measures at Baseline for All Study Participants

\begin{tabular}{|c|c|c|c|}
\hline Characteristic & $\begin{array}{l}\text { Activity } \\
\mathrm{n}=97\end{array}$ & $\begin{array}{l}\text { Social } \\
n=96\end{array}$ & $\begin{array}{c}\text { Total } \\
N=193\end{array}$ \\
\hline Female, No. (\%) & $62(63.9)$ & $51(53.1)$ & $113(58.5)$ \\
\hline Age mean (SD) & $81.4(4.8)$ & $80.8(3.9)$ & $81.1(4.4)$ \\
\hline Widowed, No. (\%) & $46(47.4)$ & $42(43.8)$ & $88(45.6)$ \\
\hline Lives alone, No. (\%) & $54(55.7)$ & $46(47.9)$ & $100(51.8)$ \\
\hline Perception of enough money, No. (\%) & $97(100)$ & $95(99.0)$ & $192(99.5)$ \\
\hline \multicolumn{4}{|l|}{ Diagnoses, No. (\%) } \\
\hline Asthma & $12(12.4)$ & $14(14.6)$ & $26(13.5)$ \\
\hline Diabetes & $12(12.4)$ & $11(11.5)$ & $23(11.9)$ \\
\hline Arthritis/rheumatism & $62(63.9)$ & $61(63.5)$ & $123(63.7)$ \\
\hline Epilepsy & $1(1.0)$ & $1(1.0)$ & $2(1.0)$ \\
\hline Parkinson's Disease & $4(4.1)$ & $2(2.1)$ & $6(3.1)$ \\
\hline Heart attack/angina & $25(25.8)$ & $29(30.2)$ & $54(28.0)$ \\
\hline Stroke & $18(18.6)$ & $10(10.4)$ & $28(14.5)$ \\
\hline Hip fracture & $6(6.2)$ & $6(6.3)$ & $12(6.2)$ \\
\hline Hospitalized in the last 12 months, No. (\%) & $32(33.0)$ & $33(34.4)$ & $65(33.7)$ \\
\hline Total prescription medications, mean (SD), No. & $6.7(3.7)$ & $6.2(3.8)$ & $6.5(3.7)$ \\
\hline ICD-10 prior depression, No. (\%) & $22(22.7)$ & $30(31.3)$ & $52(26.9)$ \\
\hline ICD-10 current depression, No. (\%) & $3(3.1)$ & $5(5.2)$ & $8(4.1)$ \\
\hline ICD-10 severe depression, No. (\%) & $2(2.1)$ & $5(5.2)$ & $7(3.6)$ \\
\hline DSM- IV diagnosis, No. (\%) & $23(23.7)$ & $29(30.2)$ & $52(26.9)$ \\
\hline Depression symptoms, GDS > 4 & $21(22)$ & $35(36.5)$ & $56(29.0)$ \\
\hline Any depression criteria met on CIDI & $29(29.9)$ & $40(41.7)$ & $69(35.8)$ \\
\hline $\begin{array}{l}\text { Any depression criteria met on CIDI or } \\
\text { GDS-15 score }>4\end{array}$ & $42(43.3)$ & $60(63.2)$ & $102(53.1)$ \\
\hline Antidepressants, No. (\%) & $28(28.9)$ & $23(24.0)$ & $51(26.4)$ \\
\hline Short-acting sedatives or benzodiazepines & $24(24.7)$ & $22(22.9)$ & $46(23.8)$ \\
\hline Long-acting benzodiazepine & $2(2.1)$ & $2(2.1)$ & $4(2.1)$ \\
\hline AMTS $<7$, No. $(\%)^{\text {a }}$ & $3(3.1)$ & $3(3.1)$ & $6(3.1)$ \\
\hline SPPB score, mean (SD) ${ }^{\mathrm{b}}$ & $7.5(3.0)$ & $7.6(2.9)$ & $7.6(3.0)$ \\
\hline NEADL score, mean (SD)c & $18.2(3.1)$ & $17.9(3.7)$ & $18.0(3.4)$ \\
\hline Chair stand test, mean (SD) ${ }^{d}$ & $1.5(1.2)$ & $1.6(1.2)$ & $1.5(1.2)$ \\
\hline GDS-15 score, mean (SD) & $3.4(2.7)$ & $4.0(2.8)$ & $3.7(2.7)$ \\
\hline SF-36 PHC score, mean (SD) ${ }^{f}$ & $39.0(11.7)$ & $39.3(11.0)$ & $39.1(11.3)$ \\
\hline SF-36 MHC score, mean (SD) ${ }^{g}$ & $51.2(9.3)$ & $48.7(9.9)$ & $50.0(9.7)$ \\
\hline $\begin{array}{l}\text { Physical activity moderate/vigorous, } \\
\text { mean (SD), min/wk }\end{array}$ & $315(428)$ & $379(500)$ & $347(465)$ \\
\hline Any falls in last year, No. (\%) & $43(44.3)$ & $42(43.8)$ & $85(44.0)$ \\
\hline
\end{tabular}

AMTS = Abbreviated Mental Test Score; GDS = Geriatric Depression Scale; ICD-10 = International Classification of Diseases 10th edition: DSM-IV = Diagnostic and Statistical Manual 4th edition; $C I D I=$ Composite International Diagnostic Interview; NEADL = Nottingham Extended Activities of Daily Living scale; SPPB = short physical performance battery; SF-36 PHC = Medical Outcomes Study Short Form 36-item physical health component subscale; SF-36 MHC = Medical Outcomes Study Short Form 36-item mental health component subscale.

Scores range from 0 to 10 ; higher score indicates greater cognition.

b Scores range from 0 to 12 ; higher score indicates better function.

Scores range from 0 to 22 ; higher score indicates greater function.

¿ Scores range from 0 to 4 ; higher score indicates greater function.

e Scores range from 0 to 15; lower score indicates better mood.

f Scores range from 0 to 100 ; higher score indicates better physical health-related quality of life.

g Scores range from 0 to 100; higher score indicates better mental health-related quality of life. depressive symptoms (Table 1). Twelve participants were members of couples, 2 in the physical activity intervention and 4 in the social control group. At least $50 \%$ of the sample had moderate or major levels of depression according to ICD-10, DSM-IV (from CIDI),

or GDS-15 criteria, and $26.4 \%$ were taking antidepressants or benzodiazepines.

Ninety-six participants were randomized to the social control group and 97 to the physical activity intervention group. After 12 months follow-up there was no differential change between the groups in the primary outcome measures. There may have been a trend toward a differential impact of the physical activity intervention on walking behavior, most notable at 6 months (interaction $P=.054$ ) (Table 2 and Figure 2). There was a significant decline in functional status (NEADL) for all participants during the 12 months $(P<.003)$ but no differential change between the physical activity and social groups $(P=.997)$. There was no differential change between the groups in physical function $\left(\mathrm{SPPB}_{i} P=.274\right)$ and no change over time $(P=.255)$. Quality of life related to mental health (SF-36 MCS) improved in the whole group over time $(P<.001)$, but there was no significant difference between the groups $(P=.240)$. Quality of life related to physical health (SF-36 PCS) did not change during the trial in the whole group $(P=.761)$, and there was no significant differential change between the groups $(P=.068)$.

GDS-15 scores improved for all participants over the year of the trial $(P<.001)$, but there was no significant difference between the 2 groups $(P=.916)$. Those in the trial sample with higher levels of depressive symptoms (GDS-15 score $>4)$ numbered $56(29 \%)$ at baseline. At 12 months' follow-up there were $34(18 \%, P=.015)$. 
Table 2. Outcomes of the DeLLITE Trial: Function, Mood, Quality of Life, Falls, and Physical Activity

\begin{tabular}{|c|c|c|c|c|c|c|c|c|c|}
\hline \multirow[b]{2}{*}{ Outcome } & \multirow[b]{2}{*}{ Baseline } & \multicolumn{4}{|c|}{ Change } & \multirow{2}{*}{$\begin{array}{l}\text { Time-Group } \\
\text { Interaction } \\
\text { F Statistic }\end{array}$} & \multirow{2}{*}{$\begin{array}{c}\text { Time-Group } \\
\text { Interaction } \\
P \text { Value }\end{array}$} & \multirow{2}{*}{$\begin{array}{l}\text { Time F } \\
\text { Statistic }\end{array}$} & \multirow{2}{*}{$\begin{array}{l}\text { Time } P \\
\text { Value }^{\text {a }}\end{array}$} \\
\hline & & $0-6 \mathrm{Mo}$ & $6 \mathrm{Mo}$ & 6-12 Mo & $12 \mathrm{Mo}$ & & & & \\
\hline \multicolumn{10}{|l|}{ Function } \\
\hline $\begin{array}{l}\text { NEADL score, } \\
\text { mean }(S D)^{b}\end{array}$ & & & & & & 0.00 & .997 & 6.19 & .003 \\
\hline Physical activity & $\begin{array}{l}18.2 \\
(0.3)\end{array}$ & $\begin{array}{l}-0.1 \\
(0.2)\end{array}$ & $\begin{array}{l}18.0 \\
(0.3)\end{array}$ & $\begin{array}{l}-0.2 \\
(0.1)\end{array}$ & $\begin{array}{l}17.8 \\
(0.3)\end{array}$ & & & & \\
\hline Social control & $\begin{array}{l}17.9 \\
(0.4)\end{array}$ & $\begin{array}{l}-0.0 \\
(0.2)\end{array}$ & $\begin{array}{l}17.9 \\
(0.4)\end{array}$ & $\begin{array}{c}-0.2 \\
(0.2)\end{array}$ & $\begin{array}{l}17.8 \\
(0.4)\end{array}$ & & & & \\
\hline $\begin{array}{l}\text { SPPB score, } \\
\text { mean (SD) }\end{array}$ & & & & & & 1.30 & .274 & 1.38 & .255 \\
\hline Physical activity & $\begin{array}{c}7.5 \\
(0.3)\end{array}$ & $\begin{array}{c}0.3 \\
(0.2)\end{array}$ & $\begin{array}{c}7.8 \\
(0.3)\end{array}$ & $\begin{array}{c}-0.2 \\
(0.2)\end{array}$ & $\begin{array}{c}7.5 \\
(0.3)\end{array}$ & & & & \\
\hline Social control & $\begin{array}{c}7.6 \\
(0.3)\end{array}$ & $\begin{array}{l}-0.0 \\
(0.2)\end{array}$ & $\begin{array}{c}7.6 \\
(0.3)\end{array}$ & $\begin{array}{c}-0.2 \\
(0.2)\end{array}$ & $\begin{array}{c}7.5 \\
(0.3)\end{array}$ & & & & \\
\hline \multicolumn{10}{|l|}{ Mood } \\
\hline $\begin{array}{l}\text { GDS-15 score, } \\
\text { mean }(S D)^{d}\end{array}$ & & & & & & 0.09 & .916 & 18.49 & $<.001$ \\
\hline Physical activity & $\begin{array}{c}3.4 \\
(0.3)\end{array}$ & $\begin{array}{l}-0.9 \\
(0.2)\end{array}$ & $\begin{array}{l}2.4 \\
(0.2)\end{array}$ & $\begin{array}{l}-0.0 \\
(0.2)\end{array}$ & $\begin{array}{l}2.4 \\
(0.2)\end{array}$ & & & & \\
\hline Social control & $\begin{array}{l}4.0 \\
(0.3)\end{array}$ & $\begin{array}{l}-0.9 \\
(0.3)\end{array}$ & $\begin{array}{c}3.1 \\
(0.3)\end{array}$ & $\begin{array}{l}-0.1 \\
(0.2)\end{array}$ & $\begin{array}{l}2.8 \\
(0.3)\end{array}$ & & & & \\
\hline $\begin{array}{l}\text { GDS-15 score }>4 \text {, } \\
\text { No. (\%) }\end{array}$ & & & & & & 1.32 & .269 & 4.30 & .015 \\
\hline Physical activity & $\begin{array}{l}21 \\
(21.6)\end{array}$ & $(-8.9)$ & $\begin{array}{l}12 \\
(12.8)\end{array}$ & $(4.3)$ & $\begin{array}{l}16 \\
(17.0)\end{array}$ & & & & \\
\hline Social control & $\begin{array}{c}35 \\
(36.5)\end{array}$ & $(-9.3)$ & $\begin{array}{l}25 \\
(27.2)\end{array}$ & $(-7.2)$ & $\begin{array}{c}18 \\
(20.7)\end{array}$ & & & & \\
\hline \multicolumn{10}{|c|}{ Health-related quality of life } \\
\hline $\begin{array}{l}\text { SF-36 PHC score, } \\
\text { mean (SD)e }\end{array}$ & & & & & & 2.73 & .068 & 0.27 & .761 \\
\hline Physical activity & $\begin{array}{c}39.0 \\
(1.2)\end{array}$ & $\begin{array}{c}0.6 \\
(0.9)\end{array}$ & $\begin{array}{c}39.5 \\
(1.2)\end{array}$ & $\begin{array}{l}-1.2 \\
(0.8)\end{array}$ & $\begin{array}{c}38.3 \\
(1.2)\end{array}$ & & & & \\
\hline Social control & $\begin{array}{l}39.3 \\
(1.1)\end{array}$ & $\begin{array}{l}-1.5 \\
(0.9)\end{array}$ & $\begin{array}{l}37.9 \\
(1.3)\end{array}$ & $\begin{array}{l}0.9 \\
(0.7)\end{array}$ & $\begin{array}{c}39.4 \\
(1.2)\end{array}$ & & & & \\
\hline $\begin{array}{l}\text { SF-36 MHC score, } \\
\text { mean }(S D)^{f}\end{array}$ & & & & & & 1.44 & .240 & 20.36 & $<.001$ \\
\hline Physical activity & $\begin{array}{l}51.2 \\
(0.9)\end{array}$ & $\begin{array}{c}3.6 \\
(0.9)\end{array}$ & $\begin{array}{l}54.7 \\
(0.7)\end{array}$ & $\begin{array}{l}0.7 \\
(0.7)\end{array}$ & $\begin{array}{l}55.4 \\
(0.7)\end{array}$ & & & & \\
\hline Social control & $\begin{array}{l}48.7 \\
(1.0)\end{array}$ & $\begin{array}{c}4.5 \\
(1.0)\end{array}$ & $\begin{array}{l}53.7 \\
(0.9)\end{array}$ & $\begin{array}{l}-1.6 \\
(0.9)\end{array}$ & $\begin{array}{l}52.7 \\
(0.9)\end{array}$ & & & & \\
\hline \multicolumn{10}{|c|}{ Physical activity } \\
\hline \multicolumn{6}{|c|}{$\begin{array}{l}\text { Auckland Heart Study Physical Activity Questionnaire, } \\
\text { walking, mean (SD), min/wk }\end{array}$} & 2.96 & .054 & 1.82 & .165 \\
\hline Physical activity & $\begin{array}{l}121.0 \\
(13.8)\end{array}$ & $\begin{array}{c}41.2 \\
(15.8)\end{array}$ & $\begin{array}{l}162.3 \\
(16.0)\end{array}$ & $\begin{array}{l}-33.5 \\
(16.4)\end{array}$ & $\begin{array}{l}128.8 \\
(14.0)\end{array}$ & & & & \\
\hline Social control & $\begin{array}{l}124.5 \\
(16.1)\end{array}$ & $\begin{array}{l}-13.3 \\
(16.1)\end{array}$ & $\begin{array}{l}115.3 \\
(13.2)\end{array}$ & $\begin{array}{c}3.5 \\
(13.9)\end{array}$ & $\begin{array}{l}119.5 \\
(16.1)\end{array}$ & & & & \\
\hline \multicolumn{6}{|c|}{$\begin{array}{l}\text { Auckland Heart Study Physical Activity Questionnaire, } \\
\text { moderate to vigorous, mean (SD), min/wk }\end{array}$} & 0.74 & .479 & 6.43 & .002 \\
\hline Physical activity & $\begin{array}{l}315.4 \\
(43.5)\end{array}$ & $\begin{array}{l}-13.0 \\
(41.6)\end{array}$ & $\begin{array}{l}302.3 \\
(33.9)\end{array}$ & $\begin{array}{l}-38.8 \\
(35.5)\end{array}$ & $\begin{array}{l}263.6 \\
(38.2)\end{array}$ & & & & \\
\hline Social control & $\begin{array}{c}379.0 \\
(51.0)\end{array}$ & $\begin{array}{l}-70.0 \\
(43.6)\end{array}$ & $\begin{array}{c}309.0 \\
(38.2)\end{array}$ & $\begin{array}{c}-87.9 \\
(27.4)\end{array}$ & $\begin{array}{c}221.1 \\
(31.7)\end{array}$ & & & & \\
\hline
\end{tabular}

GDS-15 = Geriatric Depression Scale; MHC = SF-36 MHC = Medical Outcomes Study Short Form 36-item mental health component subscale; NEADL = Nottingham Extended Activities of Daily Living Scale; SF-36 PHC = Medical Outcomes Study Short Form 36-item physical health component subscale; SPPB $=$ Short physical performance battery;

a $P$ values are for generalized linear mixed models using time as a repeated measure.

b Scores range from 0 to 22; higher score indicates greater function.

c Scores range from 0 to 12 ; higher score indicates better function.

d Scores range from 0 to 15 ; lower score indicates better mood.

e Scores range from 0 to 100; higher score indicates better physical health-related quality of life.

'Scores range from 0 to 100; higher score indicates better mental health-related quality of life. 
There was no differential effect when comparing change between the groups over time $(P=.269$, Table 2$)$.

Each group showed a similar proportion of participants who reported at least 1 fall during the trial period ( 47 or $48 \%$, and 39 or $41 \%$ for the physical and social activity groups, respectively) and adverse events related to aches, pains and fatigue were noted at the same level in both groups $(P=.744)$. Figure 2 shows changes in outcome measures with time.

Of the 97 participants receiving the physical activity intervention, $81(84 \%)$ had all the intervention visits, and only 6 had fewer than 6 visits. At the start of the program all participants were able to identify and enlist a social companion to encourage them $(n=53)$, walk with them $(n=30)$, or help them with their activity program $(n=5)$, apart from 11 participants who preferred to exercise by themselves. During the first 6 months, one-third of the participants exercised and walked at least 3 times weekly $(29 \%$ and $37 \%$ exercised and walked, respectively). Two-thirds did the exercises and walked at least twice a week $(65 \%$ and $63 \%$ exercised and walked, respectively). At 12 months, one-half the participants (55\%) exercised at least twice a week and nearly two-thirds (59\%) walked at least twice a

\section{Figure 2. Outcomes of a physical activity intervention compared with social control for older participants with depressive symptoms.}
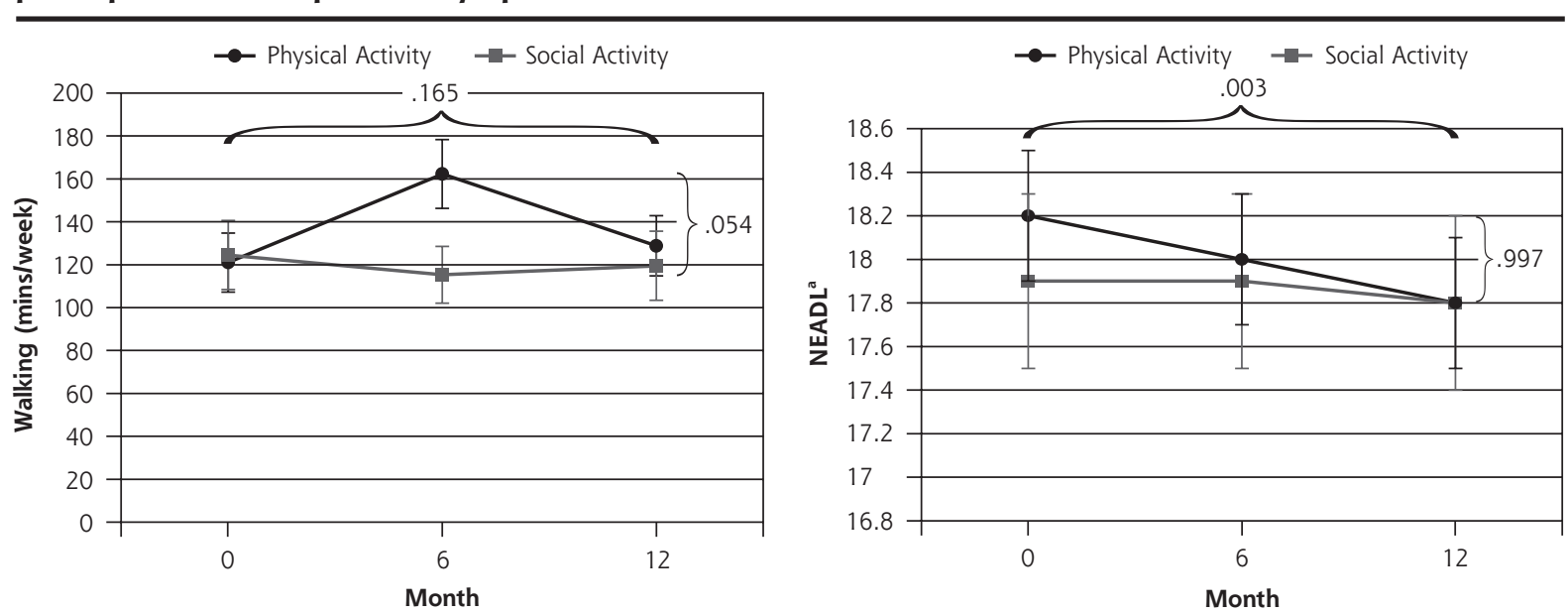

A Walking

B Function

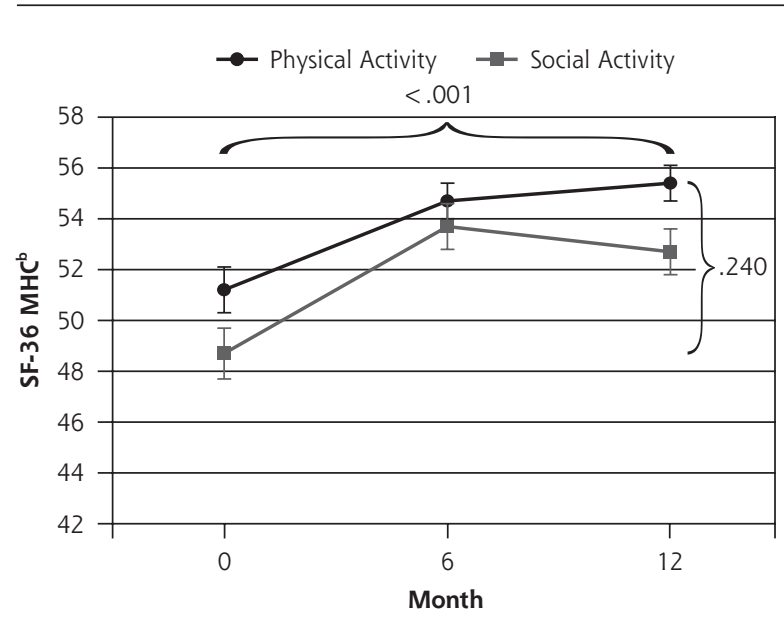

C Mental health-related quality of life

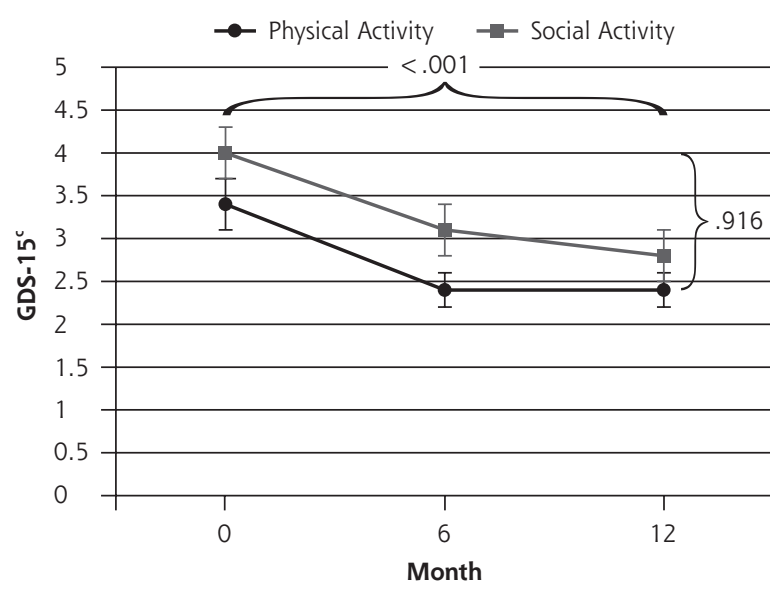

D Mood

Note: Horizontal bracket refers to the $P$ value for the change over time, and vertical bracket refers to the $P$ value for the differential change between the groups.

GDS-15 = Geriatric Depression Scale; SF-36 MHC = Medical Outcomes Study Short Form 36-item mental health component subscale; NEADL = Nottingham Extended Activities of Daily Living Scale.

${ }^{a}$ Higher score indicates greater function.

${ }^{\mathrm{b}}$ Higher score indicates better quality of life.

'Lower score indicates better mood. 
week. A quarter (25\%) exercised at least 3 times a week, and one-third (37\%) walked at least 3 times a week. Seven people did the activity program almost daily. Eighty-three (86\%) of social group participants completed all visits. Unless they had withdrawn, no participant missed the final home visit at 6 months.

Those with higher adherence to the physical activity program (achieving 3 hours of walking and 3 hours of exercising per week, $\mathrm{n}=20$ ) tended to report better physical health related quality of life, with a trend toward higher SF-36 PCS scores compared with the social group participants $(P=.073$, generalized regression model) and compared with those who achieved lower adherence $(P=.053)$ after controlling for the baseline score.

\section{DISCUSSION}

We showed no differential effect between a physical activity intervention and social visits on physical function, quality of life, or mood in a group of older primary care patients with higher levels of depressive symptoms. There was a trend toward an increase in walking behavior observed at 6 months, but other changes suggesting improved physical function failed to reach statistical significance, such as improved observed physical function (SPPB, $P=.089$ ). Those with higher levels of adherence may have had greater gains in quality of life related to physical health $(P=.053)$. All participants on average showed improvements in quality-of-life measures related to mood and mental health during the study period, indicating that depressive symptoms can improve with time and that the social visit component of the control group and intervention group was an important part of the success. The physical activity component, on the other hand, did not result in additional benefit.

The spectrum of mental health problems seen in primary care is not well described by standard diagnostic criteria. ${ }^{37}$ Although not all participants in this trial were depressed, this group of older primary care patients had high levels of depressive symptoms or depression (53\%) and were selected because screening tests were positive for depression. As those of advanced age and those with comorbidity are less likely to received treatment even when symptoms are assessed, ${ }^{38,39}$ they represent a group hard to treat in primary care ${ }^{40}$ and thus are worthy of particular attention.

This trial has essentially negative outcomes with respect to the physical activity program, and other such negative trials may not have been published. Our findings suggest a couple of points: (1) social contact may be as effective as physical activity in improving mood and quality of life for those with depressive symptoms; and (2) this home-based program did not improve physical function perhaps because either there was an insufficient dose of physical activity or the program was not able to be adhered to by this group of older people.

Social contact may be quite effective in improving mood and quality of life. The social deficit basis of depression has been well described, ${ }^{2,14,15}$ and other social interventions are acknowledged as offering benefit to those with depression. ${ }^{14,15}$ Psychotherapeutic therapies improve depression; both cognitive behavioral therapy ${ }^{41}$ and problem solving therapy have proven positive outcomes in community-dwelling older people with depression. ${ }^{42}$ The current trial, however, contained no formal psychotherapeutic component in either intervention or control arm. ${ }^{22}$ Both groups involved regular personal contact without psychotherapeutic intent, and in both groups outcomes improved. Although a causal link cannot be confirmed from the DeLLITE trial without a true control group, at least 1 other trial did have a true control group and supports our finding ${ }^{43}$ that social and physical activity are beneficial for those with depression. These findings may raise an important implication for health care practice for those aiming to increase well-being for older people.

It is important to consider why a physical activity intervention did not result in a clear improvement in function, quality of life, or mood over social visiting. Although supervised exercise has improved function in older frail people ${ }^{5}$ and reduced depressive symptoms in small trials for older people with depression compared with usual care control or health information groups ${ }^{44,45}$ the evidence on dose responsiveness of depression to exercise is mixed. ${ }^{46}$ Other trials of activity programs in the community have yielded increases in level of activity without improvement in quality of life ${ }^{47}$ or changes in quality of life without changes in physical function. ${ }^{8,48}$ It may be very difficult to improve levels of function and disability. ${ }^{49}$ Perhaps the social aspects of physical activity interventions are more important to quality of life and mood, and they led to some of the benefits observed in this trial.

Physical performance benefits and adherence rates observed in the initial trials of the Otago Exercise Program ${ }^{17}$ were not observed here. The goal-setting ${ }^{50}$ and social component added to the current activity program did not increase participation, ${ }^{51}$ and depressive symptoms may also have hindered adherence. ${ }^{52}$ Implications for practice include that greater supervision of or greater intensity of exercise may be needed to show additional physical health benefits for those with symptoms of depression. 


\section{Strengths and Limitations}

Although our results suggest that social interventions may be as effective as physical activity in improving quality of life and mood, because there was no true control, we cannot be certain that they are. We cannot truly determine whether the improvements were due to participation in the trial, to natural progression of symptoms (particularly of depressive symptoms), ${ }^{53}$ or to other initiatives in health care or changes in the wider community. Further research should include a third arm of usual care, no additional personal contact, and this study provides rationale to justify such an approach in community research. Alternatively, comparison of traditional physical activity programs with programs specifically combining social and physical activity would establish the potential additional impact on outcomes that social activity offers.

The sample size in this trial was relatively large in comparison with other trials, and the average age was older, meaning our findings have greater generalizability to the aging world population. We achieved our recruitment goal and should have been able to show change in the physical function measures if it had occurred. We also had sufficient numbers of participants to show a significant change in the GDS-15 score. The generalizability of our findings may be limited, as our response rate of $61 \%$ of eligible participants was less than desirable, but it is greater than other studies recruiting community groups for exercise programs ${ }_{1}{ }^{47}$ and those with more severe depressive symptoms may have elected not to participate. We are unable to compare those agreeing to participate with nonresponders.

A home-based physical activity program was no more successful than social visiting at improving quality of life and mood for older people with depressive symptoms. Further research could explore the impact of a social intervention against a true usual care control group.

To read or post commentaries in response to this article, see it online at http://www.annfammed.org/cgi/content/full/8/3/214.

Key words: Aged; depression; exercise; social behavior; intervention studies

Submitted April 22, 2009; submitted, revised, October 17, 2009; accepted November 10, 2009.

Author affiliations: Department of General Practice and Primary Health Care, School of Population Health, University of Auckland, Auckland, New Zealand (Kerse, Hayman, Moyes, Kiata); School of Nursing, University of Auckland, New Zealand (Peri); Department of Epidemiology and Biostatistics, School of Population Health, University of Auckland, New Zealand (Robinson); Department of General Practice, University of Otago, Wellington, New Zealand (Dowell); School of Biomedical and Health Sciences, University of Western Sydney, Sydney Australia and Centre for Physical Activity and Nutrition Research, Auckland University of Technology, Auckland, New Zealand (Kolt); Department of Psycho- logical Medicine, School of Medical and Health Sciences, University of Auckland (Hatcher); Social and Community Health, School of Population Health, University of Auckland, Auckland, New Zealand (Wiles); Department of Medicine, University of Otago, Christchurch Clinical School, Christchurch, New Zealand (Keeling).

Funding support: The New Zealand Health Research Council and the University of Auckland Research Committee funded this trial. The funders had no involvement in the research design, conduct, or interpretation of results.

This work has been presented at the 36th Annual Meeting of the North American Primary Care Research Group, November 15-19, 2008, Rio Grande, Puerto Rico; and at the New Zealand Departments of General Practice Research Retreat, September 2008, Wellington, New Zealand.

Trial registration number: Australia and New Zealand Clinical Trials Register ACTRN12605000667617.

Acknowledgments: We thank the participants; research nurses Lois Shaw and Dinah Walker; and social visitor Anthea Palmer. We are grateful to the primary care practitioners and their staff in assisting with recruitment.

\section{References}

1. Baldwin R, Chiu C, Katona C. Guidelines on Depression in Older People-Practicing the Evidence. London: Martin Dunitz Ltd; 2002.

2. Bruce ML, Hoff RA. Social and physical health risk factors for firstonset major depressive disorder in a community sample. Soc Psychiatry Psychiatr Epidemiol. 1994;29(4):165-171.

3. Guralnik JM, Ferrucci L, Simonsick EM, Salive ME, Wallace RB. Lowerextremity function in persons over the age of 70 years as a predictor of subsequent disability. N Engl J Med. 1995;332(9):556-561.

4. Blumenthal JA, Babyak MA, Moore KA, Craighead WE, Herman $S$, Khatri $P$, et al. Effects of exercise training on older patients with major depression. Arch Intern Med. 1999;25;159(19):2349-2356.

5. Gill TM, Baker DI, Gottschalk M, Peduzzi PN, Allore H, Byers A. A program to prevent functional decline in physically frail, elderly persons who live at home. N Engl J Med. 2002;347(14):1068-74.

6. Rajeski W, Mihalko S. Physical Activity and quality of life in older adults. J Gerontol A Biol Sci Med. 2001;56:23-36.

7. Hughes SL, Seymour RB, Campbell RT, Whitelaw N, Bazzarre T. Bestpractice physical activity programs for older adults: findings from the national impact study. Am J Public Health. 2009;99(2):362-368.

8. Kerse N, Elley CR, Robinson E, Arroll B. Is physical activity counseling effective for older people? A cluster randomized, controlled trial in primary care. J Am Geriatr Soc. 2005;53(11):1951-1956.

9. Wilcox S, Dowda M, Griffin SF, et al. Results of the first year of active for life: translation of 2 evidence-based physical activity programs for older adults into community settings. Am J Public Health. 2006;96(7):1201-1209.

10. McAuley E, Courneya KS, Rudolph DL, Lox CL. Enhancing exercise adherence in middle-aged males and females. Prev Med. 1994; 23(4):498-506

11. King AC, Oman RF, Brassington GS, Bliwise DL, Haskell WL. Moderate-intensity exercise and self-rated quality of sleep in older adults. A randomized controlled trial. JAMA. 1997;277(1):32-37.

12. Peri K, Kerse N, Robinson E, Parsons M, Parsons J, Latham N. Does functionally based activity make a difference to health status and mobility? A randomised controlled trial in residential care facilities (The Promoting Independent Living Study; PILS). Age Ageing. 2008;37(1):57-63.

13. Stathopoulou G, Powers MB, Berry AC, Smits JAJ, Otto MW. Exercise interventions for mental health: A quantitative and qualitative review. Clin Psychol Sci Pract. 2006;13(2):179-193. 
14. Bowling A, Farquhar M. Associations with social networks, social support, health status and psychiatric morbidity in three samples of elderly people. Soc Psychiatry Psychiatr Epidemiol. 1991;26(3):115-126.

15. Murphy E. Social origins of depression in old age. Br J Psychiatry. 1982;141:135-142.

16. Prince MJ, Harwood RH, Thomas A, Mann AH. A prospective population-based cohort study of the effects of disablement and social milieu on the onset and maintenance of late-life depression. The Gospel Oak Project VII. Psychol Med. 1998;28(2):337-350.

17. Robertson MC, Campbell AJ, Gardner MM, Devlin N. Preventing injuries in older people by preventing falls: a meta-analysis of individual-level data. J Am Geriatr Soc. 2002;50(5):905-911.

18. Kerse N, Falloon K, Moyes SA, et al. DeLLITE depression in late life an intervention trial of exercise. Design and recruitment of a randomised controlled trial. BMC Geriatr. 2008;8:12.

19. Altman D. Better reporting of randomised controlled trials: the CONSORT statement. BMJ. 1996;313(7057):571-571.

20. Guyatt GH, Sackett DL, Cook DJ. Users' guides to the medical literature. II. How to use an article about therapy or prevention. A. Are the results of the study valid? Evidence-Based Medicine Working Group. JAMA. 1993;270(21):2598-2601.

21. Arroll B, Goodyear-Smith F, Kerse N, Fishman T, Gunn J. Effect of the addition of a "help" question to two screening questions on specificity for diagnosis of depression in general practice: diagnostic validity study. BMJ. 2005;331(7521):884.

22. Wiles J, Allen $\mathrm{R}$, Kerse $\mathrm{N}$, et al. Older people, their social spaces and the significance of home: a study in Auckland, New Zealand. Soc Sci Med. In press.

23. Guralnik JM, Simonsick EM, Ferrucci L, et al. A short physical performance battery assessing lower extremity function: association with self-reported disability and prediction of mortality and nursing home admission. J Gerontol. 1994;49(2):M85-M94.

24. Essink-Bot ML, Krabbe PF, Bonsel GJ, Aaronson NK. An empirical comparison of four generic health status measures. The Nottingham Health Profile, the Medical Outcomes Study 36-item Short-Form Health Survey, the COOP/WONCA charts, and the EuroQol instrument. Med Care. 1997;35(5):522-537.

25. Brazier JE, Harper R, Jones NM, et al. Validating the SF-36 health survey questionnaire: new outcome measure for primary care. BMJ. 1992;305(6846):160-164

26. Ware J. SF-36 Physical and Mental Health Summary Scales: A User's Manual. Boston, MA: The Health Institute; 1994.

27. Sheikh J. J Y. Geriatric Depression Scale (GDS): Recent Evidence and Development of a Shorter Version. In: Clinical Gerontology : A Guide to Assessment and Intervention. New York: The Haworth Press; 1986:165-173.

28. Elley C, Kerse N, Swinburn B, Arroll B, Robinson E. Measuring physical activity in primary health care research: Validity and reliability of two questionnaires. N Z Fam Phys. 2003;30(3):171-180.

29. Hodkinson HM. Evaluation of a mental test score for assessment of mental impairment in the elderly. Age Ageing. 1972;1(4):233-238.

30. Andrews G, Peters L, Guzman A-M, Bird K. A comparison of two structured diagnostic interviews: CIDI and SCAN. Aust N Z J Psychiatry. 1995;29(1):124-132

31. Wittchen H-U, Lachner G, Wunderlich U, Pfister H. Test-retest reliability of the computerized DSM-IV version of the Munich-Composite International Diagnostic Interview (M-CIDI). Soc Psychiatry Psychiatr Epidemiol. 1998;33(11):568-578.

32. World Health Organization. Composite International Diagnostic Interview (Core version 2.1). Geneva: WHO; 1997.

33. Diagnostic and Statistical Manual of Mental Disorders (DSM), Fourth Edition (DSM-IV). Washington, DC: American Psychiatric Association; 1994.
34. International Classification of Diseases, Tenth Edition (ICD-10). Geneva: World Health Organization; 1990.

35. Hayman KJ, Kerse NM, Grow SJL, Wouldes T, Robertson C, Campbell AJ. Depression in older people: visual impairment and subjective ratings of health. Optom Vision Sci. 2007;84(11):1024-1030.

36. Campbell AJ, Robertson MC, La Grow SJ, et al. Randomised controlled trial of prevention of falls in people aged $>$ or $=75$ with severe visual impairment: the VIP trial. BMJ. 2005;331(7520):817.

37. The MaGPle Research Group. The nature and prevalence of psychological problems in New Zealand primary health care: a report on Mental Health and General Practice Investigation. N Z Med J. 2003;116(1171):U379

38. Kendrick T, Dowrick C, McBride A, et al. Management of depression in UK general practice in relation to scores on depression severity questionnaires: analysis of medical record data. BMJ. 2009; 338:b750.

39. Dowrick C, Leydon GM, McBride A, et al. Patients' and doctors' views on depression severity questionnaires incentivised in UK quality and outcomes framework: qualitative study. BMJ. 2009;338:b663.

40. Mathieson F, Collings S, Dowell A. Sub-threshold mental health symptoms: finding an alternative to the medicatioin of unhappiness. J Prim Health Care. 2009;1(1):74-77.

41. Cuijpers P, van Straten A, Smit F. Psychological treatment of latelife depression: a meta-analysis of randomized controlled trials. Int J Geriatr Psychiatry. 2006;21(12):1139-1149.

42. Ciechanowski $P$, Wagner $E$, Schmaling $K$, et al. Community-integrated home-based depression treatment in older adults: a randomized controlled trial. JAMA. 2004;291(13):1569-1577.

43. McNeil JK, LeBlanc EM, Joyner M. The effect of exercise on depressive symptoms in the moderately depressed elderly. Psychol Aging. 1991;6(3):487-488

44. Singh NA, Clements KM, Singh MA. The efficacy of exercise as a long-term antidepressant in elderly subjects: a randomized, controlled trial. J Gerontol A Biol Sci Med Sci. 2001;56(8):M497-M504.

45. Mather AS, Rodriguez C, Guthrie MF, McHarg AM, Reid IC, McMurdo ME. Effects of exercise on depressive symptoms in older adults with poorly responsive depressive disorder: randomised controlled trial. Br J Psychiatry. 2002;180:411-415.

46. Dunn AL, Trivedi MH, O’Neal HA. Physical activity dose-response effects on outcomes of depression and anxiety. Med Sci Sports Exerc. 2001;33(6)(Suppl):S587-S597, discussion 609-610.

47. Kolt GS, Schofield GM, Kerse N, Garrett N, Oliver M. Effect of telephone counseling on physical activity for low-active older people in primary care: a randomized, controlled trial. J Am Geriatr Soc. 2007; 55(7):986-992

48. Kerse N, Jolley D, Arroll B, Flicker L, Young D. Improving the health behaviours of the elderly: randomised controlled trial of a general practice education programme. BMJ. 1999; 319(7211):683-687.

49. Keysor JJ, Jette AM. Have we oversold the benefit of late-life exercise? J Gerontol A Biol Sci Med Sci. 2001;56(7):M412-M423.

50. Gyurcsik NC, Estabrooks PA, Frahm-Templar MJ. Exercise-related goals and self-efficacy as correlates of aquatic exercise in individuals with arthritis. Arthritis Rheum. 2003;49(3):306-313

51. Kolt GS, Oliver M, Schofield GM, Kerse N, Garrett N, Latham NK. An overview and process evaluation of TeleWalk: a telephone-based counseling intervention to encourage walking in older adults. Health Promot Int. 2006;21(3):201-208.

52. Morey MC, Dubbert PM, Doyle ME, et al. From supervised to unsu pervised exercise: factors associated with exercise adherence. J Aging Phys Act. 2003;11(3):351-368.

53. van Weel-Baumgarten $E$, van den Bosch W, van den Hoogen H, Zitman FG. Ten year follow-up of depression after diagnosis in general practice. Br J Gen Pract. 1998;48(435):1643-1646. 